\title{
Preface
}

HORMONE

RESEARCH IN

Horm Res Paediatr 2016;86:219-220

DOI: $10.1159 / 000449273$

Published online: September 16, 2016

PAEDIATRICS

\section{Endocrine Disruptors and Child Health: New Insights}

\author{
Stefano Cianfarani ${ }^{\mathrm{a}-\mathrm{c}}$ Olle Söder ${ }^{\mathrm{c}}$ \\ ${ }^{a}$ Dipartimento Pediatrico Universitario-Ospedaliero, Tor Vergata University, and ${ }^{b}$ Molecular Endocrinology Unit, \\ 'Bambino Gesù' Children's Hospital, Rome, Italy; 'Pediatric Endocrinology Unit, Department of Women's and \\ Children's Health, Karolinska Institutet, Stockholm, Sweden
}

This special issue of Hormone Research in Pediatrics originates from the European Society for Paediatric Endocrinology (ESPE) Developmental Seminar 'Endocrine Disruptors and Child Health' held in Rome in May 2015. The major international experts convened in Rome to present the more recent advances in the field, and the content of their talks is extensively reported in this issue.

Chemicals that affect any aspect of hormonal function are referred to as endocrine disruptors (EDs) [1]. Exposure during critical periods of development, such as fetal and early postnatal life, may have particularly critical consequences with implications in research, patient care, prevention and public health [2].

The disrupting effects of chemicals on the endocrine system have gained increasing support from many cellular and animal models. In humans, though several epidemiologic studies have linked the exposure to exogenous chemicals to a variety of endocrine and nonendocrine dysfunctions and even organ malformations, the causeeffect relationship is less clear due to the objective difficulty in studying the complexity of human-environment interactions. Fetal growth restriction, premature birth, reproductive disorders, thyroid dysfunction, alterations of pubertal timing, immune dysfunction, certain cancers, especially of the reproductive organs, birth defects of the

\section{KARGER}

() 2016 S. Karger AG, Basel

E-Mail karger@karger.com

www.karger.com/hrp genitalia and poorer sperm quality, cryptorchidism, neurological effects, neuropsychiatric disorders, diabetes, obesity and other metabolic disorders have been associated with the exposure to EDs [2]. The situation has been worrying clinicians and scientists and call-to-action statements have been published [3].

EDs are divided into major classes of chemicals including various types of pesticides, industrial chemicals, plastic packaging components, fuels and other materials that are used in daily life [1]. The exposure may occur early in life as every pregnant woman has EDs in her body and may transfer them through the placenta to the fetus and through milk to the infant. Inhalation, oral and dermal exposures are the main routes of adult exposure to environmental chemicals [2]. EDs may act via classical nuclear receptors, nonnuclear steroid hormone receptors, nonsteroid receptors, orphan receptors, enzymatic pathways involved in steroid biosynthesis and/or metabolism and other mechanisms involved in endocrine and reproductive system function. Unfortunately, the study of the biology and impacts is extremely complicated by a num-

Stefano Cianfarani

Molecular Endocrinology Unit, 'Bambino Gesù' Children's Hospital Piazza S. Onofrio 4

IT-00165 Rome (Italy)

E-Mail stefano.cianfarani@uniroma2.it

Olle Söder

Pediatric Endocrinology Unit, Q2:08, Department of Women's and Children's Health, Karolinska Institutet at Karolinska University Hospital Solna SE-171 76 Stockholm (Sweden)

E-Mail Olle.Soder@ki.se 
ber of factors. (1) Each human being is exposed to many different EDs over a lifetime and always to a mixture rather that a single compound. Exposure to low-dose mixtures of endocrine disrupting chemicals characterizes environmental conditions in human and wildlife [4]. (2) Effects may be not dose dependent, and even exposure to low doses of chemicals may induce disrupting effects. (3) Different animal species react differently to the same compound, making it impossible to reliably infer effects from the observation of what occurs in wildlife to human beings. (4) Age groups and sexes react differently. (5) EDs may have transgenerational effects with impacts on health visible only in the next generations. These generational effects are thought to be mediated via epigenetic mechanisms that transmit ED effects to the next generations in the absence of direct exposure [5].

Due to the characteristics outlined above, the field of EDs has particular pertinence to pediatric endocrinologists [3], particularly since intervention is possible. This issue collects both Mini Reviews and original data on many different aspects of endocrine disruption from fetal life to adolescence in order to update pediatric endocrinologists on EDs and, hopefully, to stimulate further research on this topic in our PedEndo community.

\section{References}

1 Diamanti-Kandarakis E, Bourguignon JP, Giudice LC, Hauser R, Prins GS, Soto AM, Zoeller RT, Gore AC: Endocrine-disrupting chemicals: an Endocrine Society scientific statement. Endocr Rev 2009;30:293-342.

2 Bergman A, Heindel JJ, Jobling S, et al (eds): State of the Science of Endocrine Disrupting Chemicals - 2012. WHO/UNEP, 2013. http://www.who.int/ceh/publications/endocrine/en.

3 Skakkebaek NE, Toppari J, Söder O, Gordon CM, Divall S, Draznin M: The exposure of fe- tuses and children to endocrine disrupting chemicals: a European Society for Paediatric Endocrinology (ESPE) and Pediatric Endocrine Society (PES) call to action statement. J Clin Endocrinol Metab 2011;96:3056-3058.

-4 Kortenkamp A: Low dose mixture effects of endocrine disrupters: implications for risk assessment and epidemiology. Int J Androl 2008;31:233-240.

5 Skinner MK: Endocrine disruptor induction of epigenetic transgenerational inheritance of disease. Mol Cell Endocrinol 2014;398:4-12. 